\title{
Bibliotecas Digitais Integradas a Ambientes Virtuais de Aprendizagem
}

\author{
Silvia de Castro Bertagnolli \\ silviacb@uniritter.edu.br \\ Morgana Magnus Wagner \\ morgana_wagner@uniritter.edu.br \\ Jonathas Samuel Rodrigues de Amorim \\ jonathas_amorim@uniritter.edu.br \\ Lauren Aparecida Barcelos Sanches \\ lauren@uniritter.edu.br \\ Centro Universitário Ritter dos Reis - UniRitter \\ Rua Orfanotrófio, 555 - Alto Teresópolis - Porto Alegre - RS - CEP 90840-440
}

\section{RESUMO}

As bibliotecas digitais possibilitam uma melhor organização das informações, servindo como suporte fundamental para o desenvolvimento da pesquisa e do ensino em uma Universidade. A educação a distância viabiliza a auto-aprendizagem, utilizando a mediação de recursos didáticos organizados de forma significativa, sendo que uma das maneiras mais adotadas é a disponibilização de materiais didáticos. Como ambas as abordagens viabilizam um novo ambiente de estudo e aprendizagem, resolveu-se realizar uma integração entre as mesmas. Pretende-se que essa integração possibilite uma produção de material didático mais significativa e que a qualidade destes seja potencializada.

Palavras-chave: bibliotecas digitais, ambientes virtuais de aprendizagem e material didático.

\section{Digital Libraries Integrated with Virtual Environments for Learning}

\begin{abstract}
The digital libraries allow better organization of information, serving as support main for development research and teaching in a university. In the E-learning provides a selflearning, using the mediation of teaching resources organized in a significant way, and that one of the most adopted is the availability of teaching materials. As both approaches provide a new environment for study and learning, resolved itself realize integration between them. It is intended that this integration enables a production of teaching materials more significant and that the quality is highlighted.
\end{abstract}

Key words: digital libraries, virtual environments for learning and teaching materials. 


\section{INTRODUÇÃO}

Atualmente, vive-se em uma sociedade denominada Sociedade da Informação, também denominada sociedade do conhecimento, na qual a evolução tecnológica da informação e da comunicação, caracterizada pelo advento da Internet, viabiliza as " [...] transformações ocorridas nas relações do homem com a ciência, a tecnologia, o conhecimento, e o trabalho" (Pinheiro, 2006). Devido esse processo, as bibliotecas tradicionais, para melhor atender aos usuários, sentiram a necessidade de acompanhar tais transformações, utilizando o ambiente digital, para oferecer seus serviços, que segundo Alvarenga (2001):

[...] pode ser definida como um conjunto de objetos digitais construídos a partir do uso de instrumentos eletrônicos, concebidos com o objetivo de registrar e comunicar pensamentos, idéias, imagens e sons, disponíveis a um contingente ilimitado de pessoas, dispersas onde quer que a plataforma WWW alcance.

As fontes de materiais da Internet compreendem em "[...] muitos milhões de unidades distribuídas em milhares de servidores, cada um com seus hardware e software próprios" (Alvarenga, 2001). Essa explosão de informação pode ocasionar dificuldade no acesso, na filtragem e na pesquisa do material desejado, devido à desorganização da rede.

A implantação de uma biblioteca digital possibilita melhor organização das informações, servindo como suporte fundamental para o desenvolvimento da pesquisa e do ensino em uma IES (Instituição de Ensino Superior). Além disso, têm-se como vantagens o material disponível a qualquer tempo, facilidade de pesquisa e de acesso, atualização das informações, diminuição dos custos e preservação do acervo. A biblioteca digital também possibilita uma maior divulgação dos materiais didáticos e dos trabalhos realizados (trabalhos acadêmicos desenvolvidos pelos alunos nas diversas disciplinas, trabalhos de conclusão de curso e, futuramente, dissertações de mestrado).

A composição do acervo digital deve levar em consideração aspectos técnicos e éticos como o formato dos dados, respeito aos direitos autorais e capacitação dos recursos humanos. O desafio imposto às bibliotecas digitais é demonstrar que elas podem ser utilizadas como recurso seguro para consultas, viabilizando um novo ambiente de estudo.

Por outro lado, têm-se os tradicionais ambientes virtuais de aprendizagem (AVAs), utilizados para Educação a Distância (EaD). Eles oferecem ferramentas que permitem a publicação de arquivos e materiais didáticos, entre diversas outras funcionalidades. Os AVAs também possibilitam a interação entre professor-aluno, aluno-professor e aluno-aluno. Os ambientes estabelecem "redes de comunicação e aprendizagem" entre os envolvidos possibilitando a troca de conhecimentos e experiências. Esses ambientes podem ser utilizados para como mediadores da comunicação em disciplinas presenciais, totalmente a distância, ou ainda, em disciplinas semipresenciais (Bertagnolli, 2007).

Constantemente professores que trabalham com esses ambientes apontam como fragilidade da $\mathrm{EaD}$ o esforço empregado na elaboração do material didático. Observouse que boa parte desse problema tem relação com o pouco conhecimento das tecnologias da informação, com a falta de habilidade no uso de certas tecnologias, e principalmente, com o pouco uso que se faz do material didático produzido. Alguns professores de turmas pequenas não se sentem motivados a criar materiais, devido à quantidade reduzida de alunos. Mesmo com o uso de AVAs esse problema não é minimizado, pois os materiais publicados nos ambientes continuam sendo disponibilizados para um conjunto limitado de alunos. 
O objetivo deste trabalho compreende descrever alguns aspectos relacionados com bibliotecas digitais e AVAs e como a integração de ambos contribui para incrementar a qualidade do material didático produzido.

A intenção é que o autor (professor, aluno ou outro envolvido com produção cientifica/cultural) ao publicar o seu material didático, no formato digital, possa disponibilizá-lo somente para uma turma específica, ou possa compartilhá-lo com um público mais abrabgente. $\mathrm{O}$ que significa dizer que o material também pode ser acessado por todos os alunos regularmente matriculados em uma determinada Instituição. Com isso, o acesso ao material produzido é mais amplo e mais dinâmico, explorando os recursos de multimídia e também a idéia de hipertexto.

Segundo Lancaster (1991, p. 168), com relação às publicações digitais tem-se que:

[...] elas serão dinâmicas e multidimensionais, ao invés de estáticas e unidimensionais. Uma descrição narrativa será apresentada como um hipertexto, reorganizável sob o controle do usuário. Muitas ilustrações estáticas serão substituídas por animação ou por modelos analógicos eletrônicos (por exemplo, ilustrações de fenômenos físicos, operações de equipamentos, realização de uma experiência).

$\mathrm{O}$ artigo prossegue apresentando na seção 1 alguns aspectos relacionados com a importância pedagógica do material didático. Após, seção 2, são realizadas algumas considerações sobre a educação a distância e as ferramentas dos Ambientes Virtuais de Aprendizagem. Na seção 3, são conceitos relevantes sobre bibliotecas digitais, já na seção 4 são apresentados alguns passos já realizados do trabalho apresentado neste artigo. Finalmente, na seção 5 encontram-se descritas algumas conclusões.

\section{MATERIAL DIDÁTICO}

Através do desenvolvimento das tecnologias da comunicação e informação, acabou surgindo uma nova pedagogia que se baseia na comunicação, a chamada Pedagogia Interativa. Essa acaba por romper com o modelo pedagógico tradicional (Freire, 1998).

Nesse novo modelo, os alunos são agentes participantes do processo de construção do conhecimento. Eles são responsáveis pelo que aprenderão e podem criar livremente a partir das informações que lhes são fornecidas. Os professores são mediadores, ou seja, guias, e o aluno terá que buscar a pesquisa para complementar o seu conhecimento. $\mathrm{O}$ discente acaba construindo um caráter crítico diferenciado que o preparará melhor para o mercado de trabalho.

As teorias de aprendizagem no processo educativo são necessárias para que se alcancem os objetivos propostos. O professor não necessita escolher uma única teoria, pode avaliar o conteúdo que deverá ser trabalhado e definir a proposta pedagógica mais adequada, mesclando-as. Por exemplo, se for utilizada uma Teoria Cognitiva, de Jean Piaget, os alunos irão interagir com o meio ambiente, físico e social, isto é, entre si e com o professor para que seja construído o conhecimento dessa matéria tecnológica. A aprendizagem pode ser entendida como a própria adaptação obtida por um processo de equilíbrio e desequilíbrio constantes. Na prática, trata-se de uma aprendizagem buscada pelo próprio sujeito segundo suas capacidades, que são resultantes das estruturas já construídas. Além da aprendizagem de conteúdos, aprende-se a aprender, pois as capacidades não são inatas, mas resultantes da interação do sujeito com seu meio (Lins, 1984).

Para que uma proposta educativa seja efetiva, precisa ser centrada no aluno. Isso só é possível se for seguido o conceito de informação mediada pedagogicamente. Sendo que, a ordem do discurso passa a ser ditada pelas necessidades de percepção e de ação dos interlocutores presentes no processo educativo (Lins, 1984). 
Vários tipos de mídias e recursos podem ser utilizados para ilustrar os materiais didáticos disponibilizados em um ambiente virtual, depende de cada contexto de disciplina ou curso. Assim, é imprescindível que o aluno tenha uma visão geral do conteúdo que terá que assimilar ao longo da disciplina.

Para Fonseca Filho (2006), o material didático não pode se limitar a textos e figuras estáticas. A interatividade precisa estar presente, e é definida como um processo de construção da comunicação, proporcionado pelo uso do computador como forma de fazer com que os alunos raciocinem e sejam críticos em relação ao assunto trabalhado. O tipo de interatividade proposta pelo meio ainda é um fator importante: síncrona, assíncrona, uni e bidirecional e a escolha deste modelo depende do Modelo Educacional e Comunicacional vigente.

Segundo Castro (2002), o material didático tem que ser uma ferramenta básica de aprendizagem, de modo que permita a auto-aprendizagem do aluno. Além disso, é necessário que seja um conteúdo motivador, variado, e que se adapte aos vários estilos de aprendizagem.

$\mathrm{Na}$ produção de materiais didáticos, é importante que a abordagem dos conteúdos seja trabalhada de forma gradativa seqüencial, do mais simples ao mais complexo. A seqüenciação poderá ser realizada através do estabelecimento de uma estratégia que permita ligações, comparações/contrastes com o suporte do texto escrito. Esse processo é complexo e envolve tratamentos pedagógicos cuidadosos para que se possam alcançar os objetivos educacionais.

Castro (2002) afirma que, os materiais produzidos têm que ter algumas características básicas:

1. interatividade - que permite ao aprendiz um papel ativo no processo de construção do seu conhecimento;

2. praticidade - disponibilizando as informações de forma fácil para que o aluno entenda os conteúdos que estão sendo trabalhados;

3. autonomia - permitindo ao aluno navegar livremente pelo conteúdo em uma estrutura que o mesmo possa escolher, propiciando um auto-estudo;

4. consistência - coerência com o plano e as metas da disciplina proposta.

Além disso, ele deve ser dialógico; incentivar a exploração; valorizar o conhecimento prévio dos alunos.

O modelo proposto assume as características de um hipertexto, que conforme Rodrigues (2006) é um documento com característica não-linear, isto é, possui ligações e conexões com várias informações e idéias. As informações podem ser ligadas, conforme a necessidade do professor que está construindo o material didático, possibilitando a construção de suas próprias rotas e seqüências. $\mathrm{O}$ ideal na produção do material é que ele utilize hipertextos que contenham ilustrações, links, e que o texto esteja em uma linguagem mais informal e sucinta.

Observa-se que ao considerar os materiais didáticos, alguns tipos de mídia são importantes de serem utilizados, sendo que os principais compreendem (Castro, 2002):

1. textos impressos, revistas, livros e textos virtuais - apresentam a informação de forma clara, seqüencial, que desperta o interesse do aluno;

2. figuras: exemplificam o conteúdo;

3. animação: dinamiza, motiva, simula os assuntos abordados;

4. áudio: atrai a atenção, reforça e contextualiza a integração;

5. vídeo: possibilita ao aluno uma melhor observação da realidade;

6. software: permite interatividade entre os participantes do processo de aprendizagem;

7. hipermídia: incentiva o aluno a pesquisar em mecanismos de busca e outras mídias. 
Já Sangrá (2000), menciona que os recursos metodológicos utilizados nos cursos podem ser divididos em seis grupos:

1. aplicações de aprendizagem (por exemplo, simulações, jogos e estudos de caso);

2. grupos de discussão (por exemplo, fóruns, chats);

3. perguntas Abertas (por exemplo, atividades de questionários);

4. perguntas Fechadas (por exemplo, provas de múltipla escolha);

5. apresentação de Informação (por exemplo, leituras, gráficos e apresentação de exemplos);

6. síntese: (por exemplo, resumos, glossários).

A partir das recomendações enumeradas e descritas previamente tem-se um ponto de partida para o desenvolvimento de materiais didáticos de qualidade $\mathrm{e}$ consistentes.

Refletindo sobre a importância de uma biblioteca digital ou de um AVA, percebe-se que há necessidade de democratização das Tecnologias da Informação, trazendo benefícios a toda comunidade, mas preservando os direitos dos autores independentemente do tipo de mídia que se está utilizando.

\section{EAD E AVAs}

Atualmente, a informação está disponível aos indivíduos através das tecnologias de informação, que são responsáveis pelas transformações na sociedade. O que mais influenciou o uso acentuado dessas tecnologias foi a Internet (Castells, 2000).

A noção de distância e de tempo, assim como de sociabilidade, também sofreu alterações com o advento da Internet. A interconexão na rede viabiliza a aproximação das pessoas através do acesso a uma variedade cada vez maior de informações e de oportunidades de lazer, cultura e serviços, que levam ao intercâmbio de pessoas com interesses afins, mesmo estando distantes fisicamente (Castells, 2000).

Nesse contexto, surge a educação a distância, que foi introduzida no sistema educacional brasileiro em 23 de dezembro de 1996, com a Lei 9.394/96 - Lei de Diretrizes e Bases na Educação. Ela abriu a possibilidade de uma nova modalidade de organização das atividades de ensino e aprendizagem, amparada no artigo 81, com a viabilização de cursos experimentais, e, mais especificamente em Educação a Distância, amparado pelo artigo 80 da mesma lei.

A educação a distância baseia-se no princípio da interação entre aluno-professor, professor-aluno, e entre aluno-aluno, tendo como mediador um AVA. Esses sistemas são disponibilizados via Internet e, para utilizá-lo, os alunos e/ou professores devem possuir um computador conectado à Internet e um navegador (como por exemplo, o Internet Explorer) atualizado. Todos os recursos de ensino e comunicação residem na própria rede, não sendo preciso instalar, na maioria dos casos, nenhum software adicional.

O ambiente de aprendizagem viabiliza uma aprendizagem mais dinâmica, baseada na pesquisa e na constante busca pelo conhecimento (Bertagnolli, 2007). Ao realizar um estudo comparativo de diversos ambientes percebeu-se um conjunto comum de ferramentas, que possibilitam uma maior interação. Entre elas destacam-se as seguintes:

- fóruns de discussões - é um repositório de conhecimento assíncrono. Um local onde dúvidas, dicas e sugestões ficam armazenadas no sistema;

- sessões de chat - é um ambiente para a troca de mensagens instantâneas, no qual os professores podem disponibilizar a seus alunos várias salas para debate;

- agendamento de tarefas - tarefas criadas pelos professores, que simulam provas virtuais de cunho avaliativo; 
- notificações/avisos - é uma ferramenta que disponibiliza ao professor o recurso de comunicar eventos a seus alunos, como: provas, trabalhos, palestras;

- mensagens eletrônicas - uma ferramenta que possibilita a troca de e-mail entre os envolvidos no processo de aprendizagem;

- armazenamento de arquivos -ferramenta que permite aos professores disponibilizar ou armazenar o material didático utilizado ora para aulas presenciais ora para aulas a distância.

Observa-se que dessas ferramentas uma das mais usadas é a que permite o armazenamento de arquivos, pois é através dela o material didático é disponibilizado. Por outro lado, esse tipo de ferramenta restringe o acesso ao material, pois na maioria dos casos ele é associado à disciplina ou a uma turma.

Seguindo essa estrutura a disseminação da informação fica limitada, isso pode influenciar o envolvido tanto positivamente, quanto negativamente. Isso se deve ao fato de que o indivíduo deve possuir um posicionamento crítico "frente aos acontecimentos políticos, econômicos e sociais da sociedade". Ou seja, é sua a tarefa de selecionar e interpretar a informação e decidir se ela pode ser empregada em um contexto e se ela pode ser usada de forma adequada.

\section{BIBLIOTECA DIGITAL}

A evolução das bibliotecas foi determinada pelas tecnologias vigentes em cada época. Em um primeiro momento tem-se a biblioteca tradicional com seu acervo impresso e espaço físico bem delimitado. Depois, a biblioteca passa a utilizar os computadores para os serviços de catalogação, indexação e organização do acervo. E, finalmente, com o desenvolvimento "[...] da internet, a biblioteca ganha nova dimensão: deixa de ser somente um espaço físico e ganha um novo espaço - o ciberespaço." (Ohira e Prado, 2002, p. 61). Marcondes e Sayão (2001) também reforçam a criação desse novo ambiente de acesso e disseminação do conhecimento em escala global, viabilizado pela convergência das tecnologias de comunicação e informação.

Esse novo modelo de biblioteca é uma resposta ao fenômeno da explosão informacional, que decorre do uso integrado dessas tecnologias. Essa grande quantidade de informação armazenada e disponibilizada pela internet apresenta o problema da identificação de informação relevante. Os mecanismos de busca gerais e os portais temáticos oferecem soluções parciais para a localização de informações na rede, principalmente as de interesse para a ciência e a tecnologia. De acordo com Marcondes e Sayão (2001, p. 26) esses mecanismos apresentam os seguintes problemas:

[...] baixa qualidade da indexação, por ser feita automaticamente, que resulta em grande quantidade de informações recuperadas, a maioria sem relevância (em termos de recuperação de informação, oferecem alta revocação, mas baixa precisão); cobertura parcial da internet; as ferramentas não são especializadas; indexam páginas HTML isoladas, e não recursos; além disto, grande quantidade de informações disponíveis na Internet estão sob a forma de registros contidos em bases de dados, que ficam assim 'escondidas'; estes registros são acessados somente por meio das interfaces destas bases de dados, o que pressupõe uma interação entre um usuário humano com a base de dados $[\ldots]$.

Devem às bibliotecas auxiliar os pesquisadores na obtenção de documentos armazenados na rede, adotando mecanismos que proporcionem a disseminação e a recuperação da informação científica digital. Com esse intuito surgem, como conseqüência, propostas de biblioteca eletrônica, virtual, digital, entre outras, que já pressupõem todo o trabalho prévio de automação de catálogos e de acesso on-line a bancos de dados e cujo objetivo é tornar disponível ao usuário os recursos de informação digitalizada. 
Para Marchiori (1997) a biblioteca digital é aquela onde as informações se apresentam somente de forma digital, não contendo documentos impressos e permitindo a pesquisa e a visualização dos documentos (em texto completo, vídeos, etc.), tanto local como remotamente, por meio da Internet.

A biblioteca digital acompanha a expansão dos horizontes do ensino e da pesquisa, ao proporcionar acesso aos materiais informacionais, sem preocupação com conceitos como lugar e quantidade disponível, mantendo, num ambiente diferenciado, a missão de uma unidade de informação de apoio bibliográfico ao ensino e à pesquisa desenvolvidos na instituição.

Alguns autores tecem considerações sobre a necessidade do domínio de algumas técnicas para o sucesso da construção e manutenção do acervo digital como:

-procedimentos da submissão de documentos digitais, considerando aspectos de workflow com especificações técnicas e legais;

-digitalização e registro de acesso ao acervo;

-implementação de interface do usuário com o acervo digital, com inclusão de recursos para recuperação de informação;

-controle e registro de acesso ao acervo;

-sistemática de empréstimo de documentos digitais;

-tratamento de direito autoral, cuja preocupação deve estar presente nas sistemáticas de controle e de registro de acesso, nos contratos elaborados durante a submissão de documentos e, fundamentalmente, quando tratamos de empréstimo digital. (Gonzales et. al., 2001, p.110).

Dentre essas técnicas os autores salientam o tratamento específico aos documentos escritos que serão disponibilizados na biblioteca digital e passarão pelo processo de digitalização para seu armazenamento. Outra técnica destacada é o controle de registro de acesso aos documentos, referindo-se à integridade do conteúdo do texto, protegidos de possíveis, mas indevidas alterações. O próprio avanço da tecnologia da informação torna a preservação dos documentos digitais cada vez mais difícil de projetar e otimizar. Por isso, dentro do ambiente de uma biblioteca digital, ambas as técnicas, de digitalização dos documentos e da segurança de controlar e registrar os acessos são fundamentais para assegurar o direito autoral.

Conclui-se que a biblioteca digital não vem substituir as bibliotecas tradicionais, mas acrescentar aos usuários outras opções de acesso às informações científicas, proporcionando o rápido acesso à informação e também o uso simultâneo de um mesmo documento.

\section{METODOLOGIA DE PESQUISA E DESENVOLVIMENTO}

O projeto partiu da idéia de comparar bibliotecas digitais e AVAs, de forma a identificar elementos comuns. A comparação de uma biblioteca digital compreendeu uma análise de sistemas de bibliotecas digitais baseados na filosofia de software livre encontrados na literatura. Para tanto, foram levadas em consideração às argumentações de Marchiori (1997) sobre a importância de se investigar, antes de iniciar o projeto de implantação da biblioteca digital, o trabalho de outras instituições e os recursos disponíveis no mercado da tecnologia da informação, que evolui muito rapidamente, com o intuito de manter atualizado e pronto para possíveis mudanças que podem ocorrer durante o processo.

Já com relação aos ambientes virtuais de aprendizagem foi realizado um estudo comparativo dos diversos AVAs encontrados na literatura, cujo objetivo foi verificar a existência ou não de uma ferramenta para armazenamento de arquivos. Após esse comparativo, chegou-se a conclusão de que essa ferramenta é indispensável nos AVAs atuais, sejam eles livres ou proprietários.

O segundo passo diz respeito à integração de bibliotecas digitais e AVAs, ou seja, o armazenamento de arquivos no AVA também pode ser disponibilizado para a 
biblioteca digital, e vice-versa. Para tanto, o produtor do material submete o seu material para avaliação de um moderador que realiza uma validação dos direitos autorais $^{1}$ do referido material. Isso porque essa estratégia para o resgate da informação, onde o texto completo de documentos está disponível on-line, deve necessariamente estar de acordo com um modelo que:

-contemple os aspectos legais, inclusive o pagamento dos direitos autorais de autor e que viabilize tanto a criação de acervo digital próprio como a criação de links para outras bibliotecas digitais;

-contemple mecanismo de pesquisa necessariamente eficiente, haja vista a quantidade e diversidade de documentos digitais existentes;

-mantenha um controle seguro de acesso e registro de acesso. (Gonzales et. al., 2001, p.102).

A alimentação desta base comum, que será compartilhada por ambas as abordagens, ocorrerá, conforme previsto pelo projeto, em três momentos: inicial, intermediário e estável.

No inicial o autor disponibiliza arquivos de sua autoria, confecciona títulos inéditos ou reedita algum existente, de modo a disponibilizá-lo. Ele pode ainda estabelecer ligações com materiais complementares, tais como outras bibliotecas, sites, e-books, entre outros. Ainda nesse momento, abre-se a possibilidade da criação de uma produção conjunta (mais de um autor) de materiais pedagógicos.

Considerando o período intermediário, vislumbra-se a publicação de material, produzido por voluntários, que possam ser disponibilizados para todos que tenham acesso ao AVA e a biblioteca digital, estabelecendo um link com as disciplinas.

Acredita-se com isso atingir uma estabilidade na integração planejada e seja possível buscar parcerias institucionais com o intuito de ampliar ou potencializar o acervo como ferramenta de complementação da aprendizagem.

\section{CONCLUSÕES}

A biblioteca digital não vem substituir as bibliotecas tradicionais, mas acrescentar aos usuários outras opções de acesso às informações científicas, proporcionando o rápido acesso à informação e também o uso simultâneo de um mesmo documento. Esta é uma verdade incontestável tanto para o ensino presencial quanto para o ensino a distância. Constata-se, portanto, que a biblioteca digital é outra opção para que os sistemas de informação proporcionem um apoio real no aumento da qualidade do ensino e no desenvolvimento científico e tecnológico.

Acredita-se que integração de AVAs e bibliotecas digitais pode se mostrar uma solução adequada para atender alunos de cursos presenciais, a distância e semipresenciais, visto que amplia o acesso a um material pedagógico de qualidade e completo. Além disso, pode incrementar a produção científica e estimular novas produções.

\section{Referências Bibliográficas}

ALVARENGA, L. A Teoria do Conceito Revisitada em Conexão com Ontologias e Metadados no Contexto das Bibliotecas Tradicionais e Digitais. DataGramaZero, Revista de Ciência da Informação, v. 2, n. 6, dezembro, 2001.

\footnotetext{
${ }^{1}$ No Brasil, atualmente essa matéria é regulada pela Lei n. ${ }^{\circ} 9.610$, de 19 de Fevereiro de 1998.
} 
BERTAGNOLLI, S. C.; SILVEIRA, S. R.; MOREIRA, E. N.; SANCHES, L. A. B. O Uso de Atividades Semipresenciais em Cursos Presenciais como Forma de Qualificação da Educação Superior: o caso do UniRitter. Revista Novas Tecnologias na Educação, v. 5, n. 1, julho, 2007.

CASTEllS, M. A Sociedade em Rede. A era da informação: economia, sociedade e cultura. São Paulo: Paz e Terra, 2000. v. 1.

CASTRO, N. J. O Estudo a Distância com o Apoio da Internet. Rio de Janeiro, 2002. Disponível em: <http://www.abed.org.br/publique/cgi/cgilua.exe/sys/start.htm?amp\%3puBUserActiveTemplate $=4$ abed $\&$ infoid $=137 \& \operatorname{sid}=116 \& \mathrm{tpl}=$ printerview $>$. Acesso em: 19 dez. 2006.

FILHO FONSECA, H.; SOUSA, G. M. de.; TAVARES, W. N. Desenvolvimento de Material Didático Dinâmico como Objeto de Aprendizagem para Ensino a Distância de Geoprocessamento. São Paulo, 2004. Disponível em: <http://www.abed.org.br/seminario2004/TCB2009.htm>. Acesso em: 19 dez. 2006.

FREIRE, Paulo. Pedagogia da autonomia: saberes necessários à prática educativa. São Paulo: Paz e Terra, 1998.

GONZALEZ, Marco; POHLMANN FILHO, Omer; BORGES, Karen Selbach. Informação digital no ensino presencial e no ensino a distância. Ciência da Informação, Brasília, v. 30, n. 2, p.101-111, maio/ago. 2001.

LANCASTER, F.W. Indexação e resumos: teoria e prática. Brasília : Briquet de Lemos Livros, 1991. p. 268-269.

LINS, Maria Judith Sucupira da Costa. A estruturação da inteligência do pré-escolar segundo Piaget. Rio de Janeiro: Anima. 1984, p. 27-72: Conceito da inteligência na teoria de Piaget.

MARCHIORI, P. Z. "Ciberteca" ou biblioteca virtual: uma perspectiva de gerenciamento de recursos de informação. Ciência da Informação, Brasília, v. 26, n. 2, 1997. Disponível em: <http://www.scielo.br/pdf/ci/v26n2/v26n2-1.pdf>. Acesso em: 02 jan. 2007.

MARCONDES, Carlos Henrique; SAYÃO, Luís Fernando. Integração e interoperabilidade no acesso a recursos informacionais eletrônicos em C\&T: a proposta da Biblioteca Digital Brasileira. Ciência da Informação, Brasília, v. 30, n. 3, p. 24-33, set./dez. 2001.

OHIRA, Maria Lourdes Blatt; PRADO, Noêmia Choffen. Bibliotecas virtuais e digitais: análise de artigos de periódicos brasileiros (1995/2000). Ciência da Informação, Brasília, v. 31, n. 1, p.61-74, jan./abr. 2002.

PINHEIRO, E. G.; MORAIS, P. S. Biblioteca Universitária, Tecnologia da Informação e Direitos Autorais: quando o eco das perguntas faz sentido. In: SEMINÁRIO NACIONAL DE BIBLIOTECAS UNIVERSITÁRIAS, 2006, Salvador. Anais do XIV Seminário Nacional de Bibliotecas Universitárias, 2006. 
RODRIGUES, A.P., et al. Produção do Material Didático para o Módulo "Ferramentas de Autoria para a Produção de Hipertexto na Educação" do Programa Mídias na Educação. Disponível em: $<$ http://portal.mec.gov.br/setec/arquivos/pdf/nilo_cefetpe-lotaslotas_midias.pdf>. Acesso em: 26 dez. 2006.

SANGRÁ, A. EaD. Catalunya: Universitat Oberta de Catalunya, 2000. 